UDC 340.116:004.738.5

LBC 67.081

\title{
TRANSFORMATION OF LEGAL SYSTEM UNDER THE INFLUENCE OF THE INTERNET ${ }^{1}$
}

\author{
Marina L. Davydova \\ Volgograd State University, Volgograd, Russian Federation
}

Vladislav O. Makarov

LEGION Bar Association of the Volgograd Region, Volgograd, Russian Federation

\begin{abstract}
Introduction. Changes in the modern world, due to the development of the Internet, have had an impact on the legal system. The purpose is to study the transformation of the legal system under the influence of the Internet. The objectives are to determine the operating concept of the legal system, the factors affecting it, as well as to highlight the elements of the legal structure of the system; to research the transformation of these elements under the influence of the Internet. The methods include general logical methods (analysis, synthesis, induction, deduction), system-structural, formal logic. Results. The legal system has such attributes as dynamism, adaptability, openness, and functioning as a kind of social system. It is determined by economic, political, national, moral, information and other factors. But the Internet is a complex factor that expresses itself in all these groups of factors and transforms the legal system, which includes elements such as the objective law, legal practice, legal infrastructure and legal consciousness. Conclusion. Objective law develops due to the emergence of the complex inter-branch institute Internet law and to a modification of other branches of law. The Internet also ensures electronic publishing of a law, provides public access to the stages of adoption of a law, and improves the procedure of legislative initiatives. The transformation of the legal infrastructure under the influence of the Internet is based on e-government concept that is developing in two directions: optimization of relations between the public authorities, and better cooperation between public and private parties. As a result of the Internet's impact on the legal practice, new legal procedures and subjects appear. It implements the principle of transparency and the rule of law, as well as access to justice. Transformation of legal conciseness under the influence of the Internet is associated with the increase in transparency of the legal system. For theoretical legal conciseness the Internet creates a new subject area of study. For the professional legal conciseness the Internet creates new objectives to solve. Moreover, ordinary conciseness can be transformed both in the direction of development, and in the direction of degradation depending on the quality of the legal information from the Internet.
\end{abstract}

Key words: legal system, Internet, system of law, legal practice, legal infrastructure, legal consciousness.

УДК 340.116:004.738.5

ББК 67.081

ТРАНСФОРМАЦИЯ ПРАВОВОЙ СИСТЕМЫ ПОД ВЛИЯНИЕМ СЕТИ ИНТЕРНЕТ ${ }^{1}$

\author{
Марина Леонидовна Давыдова \\ Волгоградский государственный университет, г. Волгоград, Российская Федерация \\ Владислав Олегович Макаров \\ Коллегия адвокатов Волгоградской области «ЛЕГИОН», г. Волгоград, Российская Федерация
}

Введение: изменения в современном мире, вызванные развитием сети Интернет, оказали свое влияние и на правовую систему. Целью работы является исследование трансформации правовой системы под влиянием сети Интернет, в связи с чем выделяются следующие задачи: определить факторы, влияющие на 
правовую систему, а также выделить элементы структуры правовой системы, исследовать трансформацию каждого элемента под влиянием сети Интернет. Методологическую основу исследования составили как общенаучные, так и специальные юридические методы познания. Результаты: правовая система детерминирована экономическими, политическими, национальными, нравственными, информационными и иными факторами. При этом сеть Интернет является комплексным фактором, находящим выражение практически во всех группах факторов и трансформирующим правовую систему. Выводы: влияние сети Интернет на развитие объективного права связано с обособлением комплексного межотраслевого института - интернет-права и изменением иных отраслей права, а также с появлением электронного опубликования, обеспечением общественного доступа к стадиям принятия и рассмотрения нормативных актов в электронной форме, расширением возможностей законотворческой инициативы. Трансформация правовой инфраструктуры под влиянием сети Интернет обусловлена появлением концепции электронного государства, развивающейся в двух направлениях: оптимизация отношений между государственными (муниципальными) органами и улучшение взаимодействия между ними и гражданами (организациями). В результате влияния Интернета на юридическую практику появляются новые юридические процедуры, субъекты, изменяется документальная форма, что в итоге способствует реализации принципов гласности и законности, а также обеспечивает доступ к правосудию. Трансформация правосознания связана с увеличением открытости правовой системы. Для теоретического правосознания Интернет в первую очередь создает новую предметную область изучения. Влияние сети Интернет на профессиональное правосознание обусловлено появлением новых задач для разрешения в рамках юридической деятельности. Обыденное же правосознание может трансформироваться как в сторону развития, так и в сторону деградации, в зависимости от качества правовой информации, получаемой из сети Интернет.

Ключевые слова: правовая система, Интернет, система права, юридическая практика, правовая инфраструктура, правосознание.

\section{Введение}

В числе факторов, оказывающих влияние на развитие современного права, Интернет занимает, вероятно, наиболее заметное положение [7, с. 298-301]. Фундаментальные исследования той роли, которую информационно-коммуникационные технологии сыграли и продолжают играть в истории человеческой цивилизации, остаются пока делом будущего. Но уже сейчас можно сказать, что влияние их на правовую реальность не ограничивается появлением новых объектов регулирования или способов передачи информации, а затрагивает все элементы правовой системы, приводя к ее существенной трансформации.

\section{Сеть Интернет как комплексный фактор}

Развитие правовой системы обусловлено наличием у нее таких признаков, как динамизм, адаптивность, открытость, а также функционирование в качестве разновидности сочиальной (общественной) системь [5, с. 49-53]. Говоря о правовой системе как разновидности социальных систем, необходимо отметить, что ее возникновение, развитие и функционирование тесным образом связаны с экономической и политической системами общества, его культурной и духовной средой в целом. Правовая система открыта, ее функционирование происходит с учетом информации, поступающей в нее из различных сфер. Обладая признаком адаптивности, система трансформируется вследствие изменений в обществе. Нестатичность, подвижность правовой системы обеспечивают ее развитие и функционирование. В.Н. Карташов указывает, что правовая система общества детерминирована экономическими, политическими, национальными, нравственными и иными факторами [5, с. 49]. Этот перечень, вероятно, можно расширить, добавив в него исторические, технические, религиозные, культурные, информационные и другие факторы.

На наш взгляд, сеть Интернет и распространение информационно-коммуникационных технологий являются комплексным фактором, находящим свое отражение практически во всех вышеперечисленных группах. Например, массовое нарушение авторских и смежных прав вследствие новых возможностей сети Интернет влечет за собой серьезные экономические последствия в виде упущенной выгоды правообладателей, что ставит перед 


\section{ТЕОРИЯ И ПРАКТИКА ГОСУДАРСТВЕННО-ПРАВОВОГО РАЗВИТИЯ}

правовой системой актуальные проблемы и требует появления новых действенных механизмов защиты нарушенных прав. Экстерриториальность сети Интернет создает сложности для традиционных механизмов администрирования [6, с. 302-305]. Увеличение объема информации, а также рост технических возможностей ее получения создают новые требования к распространению правовой информации, а также к информационной открытости государственных и муниципальных органов. Возрастает влияние и технических факторов, поскольку сама специфика информационных отношений предполагает усложнение имеющихся и появление новых технических средств, обеспечивающих функционирование информационно-правовых норм. Открытость и доступность информации, в свою очередь, все чаще затрагивают нравственные аспекты, порождая вопросы о границах информационной свободы и необходимости ограничительных мер.

Таким образом, влияние сети Интернет на правовую систему может быть оценено в контексте экономических, политических, этических, культурных и иных факторов и не сводимо к любому из них в отдельности. Сеть Интернет - масштабное явление. Его воздействие на правовую систему носит комплексный характер, позволяющий, как нам представляется, говорить не столько о частных изменениях, сколько о трансформации всей системы в целом. Во всяком случае результаты этого воздействия обнаруживаются при рассмотрении каждого структурного элемента правовой системы.

\section{Структура правовой системы}

Для того чтобы обосновать сказанное, выделим основные элементы, входящие в структуру правовой системы. По мнению В.Н. Карташова, это объективное право, взятое в единстве и взаимодействии его содержания и формы, юридическая практика (деятельность и социально-правовой опыт), осуществляемая в рамках правовых отношений и иных юридических связей, и правосознание, которое находит выражение во всех названных элементах $[5$, с. 60]. Данную схему следовало бы дополнить организационным элементом, который упоминался еще в класси- ческой монографии 1986 г. под редакцией А.М. Васильева [9, с. 39]. В.Н. Синюков, характеризуя российскую правовую систему, также уделяет значительное внимание правовым учреждениям: правоохранительным органам, правосудию и судебной системе [11, c. 464-533] - всему тому, что можно назвать институциональным уровнем системы или правовой инфраструктурой.

По нашему мнению, в качестве операциональной модели структуры правовой системы, подходящей для исследования трансформации последней под влиянием сети Интернет, может быть использована следующая:

1) объективное право (система права и система законодательства);

2) юридическая практика;

3) правовая инфраструктура;

4) правосознание.

\section{Влияние сети Интернет на объективное право}

Объективное право находит свое выражение в единстве системы права и системы законодательства. Развитие системь права связано в первую очередь с формированием новых отраслей и институтов, а также с появлением нового содержания в традиционных отраслях. Наиболее наглядно этот процесс иллюстрируется обособлением комплексного межотраслевого института - $u н$ тернет-права, обладающего собственными предметом и методом правового регулирования. Динамика развития интернет-права позволяет сделать вывод о постепенном формировании отдельной и самостоятельной отрасли права, сопровождаемом ростом нормативного правового материала, регулирующего сеть Интернет.

Стоит, однако, признать, что само по себе появление нового правового института и даже отрасли еще не дает оснований для того, чтобы говорить о трансформации всей системы права. Появление космического права или развитие нанотехнологий $[1$, с. 66-72] тоже повлекли принятие соответствующих правовых норм, но не оказали существенного влияния на содержание других отраслей права.

В этом смысле Интернет существенно отличается от других «новинок» тем, что его 
влияние может быть обнаружено практически в каждой отрасли права. Вот лишь несколько примеров.

Существенные изменения происходят в сфере гражданского права, особенно в рамках авторского права, что обусловлено появлением новых доступных технических способов распространения информации. Новые правовые механизмы появляются в сфере администрирования. Причем чем больше государство вмешивается в информационную сферу и стремится контролировать Интернет, тем больше развивается данная часть $а д$ министративного права. В рамках уголовного права появляются новые объекты преступлений, составы, а также специфические средства борьбы (например, специализированные отделы по борьбе с киберпреступностью). Интернет меняет и трудовые правоотношения, поскольку позволяет работать удаленно (в результате чего появляется так называемый фриланс). Существенно меняется прочессуальное право, получившее возможности электронного опубликования судебных актов, введения процедур упрощенного судопроизводства и расширения общей информатизации судебного процесса. Электронные механизмы также появляются в таможенном, налоговом (электронное декларирование), избирательном (ГАС «Выборы») и иных отраслях права.

Трансформация системы законодательства, естественно, также не ограничивается количественным приростом нормативных правовых актов за счет актов, регулирующих сеть Интернет. Гораздо важнее тот факт, что постепенно меняется как форма нормативного акта, так и способы его официального распространения, акцент в котором делается на электронной форме опубликования, а также на работе с электронной формой самого правового акта (например, информационно-правовая система «Законодательство России»). Создаются предпосылки для качественного изменения принимаемых законов посредством общественного доступа к стадиям принятия и рассмотрения нормативных актов в электронной форме, а также посредством возможности предложения потенциальных законотворческих инициатив, используя установленные законом интернет-формы [2].

\section{Влияние сети Интернет на правовую инфраструктуру}

Переходя к вопросу о трансформации правовой инфраструктуры под влиянием сети Интернет, необходимо отметить, что наиболее существенное влияние на этот процесс оказала концепция электронного государства. Функционирование электронного государства и развитие правовой инфраструктуры происходят в следующих направлениях:

1) отношения между государственными (муниципальными) органами;

2) отношения между государственными (муниципальными) органами и гражданами (организациями).

Основной задачей первого направления является оптимизация государственного управления, выражающаяся в дистанционном и электронном характере взаимодействия между субъектами государственного управления. Данное явление получило свое активное развитие в последние годы. В частности, действует Стратегия развития информационного общества в Российской Федерации, утвержденная Президентом РФ 7 февраля 2008 г. № Пр-212. Также приняты Указ Президента РФ «Об основных направлениях совершенствования системы государственного управления» от 7 мая 2012 г. № 601, Указ Президента РФ «О Концепции правовой информатизации России» от 28 июня 1993 г. № 966 (ред. от 22 марта 2005 г.), Постановление Правительства РФ «Об утверждении государственной программы Российской Федерации "Информационное общество" (2011-2020 годы)» от 15 апреля 2014 г. № 313 (ред. от 17 июня 2015 г.).

Главными задачами второго направления информатизации правовой инфраструктуры являются: обеспечение доступа к информации [12]; прием обращений граждан и организаций в электронной форме; дистанционное предоставление государственных услуг посредством специализированных интернет-ресурсов (например, сервис «Госуслуги»). Их качественная реализация позволяет снизить нагрузку на государственный аппарат, сократить время выполнения различных действий, сэкономить денежные средства, минуя бумажные средства связи, облегчить взаимодействие 


\section{ТЕОРИЯ И ПРАКТИКА ГОСУДАРСТВЕННО-ПРАВОВОГО РАЗВИТИЯ}

граждан с органами государства и местного самоуправления, а также повысить открытость правовой инфраструктуры, что является средством общественного контроля.

\section{Влияние сети Интернет на юридическую практику}

Сеть Интернет существенным образом повлияла и на юридическую практику, которая представляет собой самостоятельную подсистему, включающую деятельность и социально-правовой опыт. Содержание юридической деятельности состоит из субъектов и участников, юридических действий и операций, правовой техники, тактики и стратегии, результатов и иных элементов.

Неотъемлемой частью юридической деятельности являются ее внутренняя (процедурно-процессуальная) и внешняя (прежде всего документальная) формы [5, с. 60]. Поэтому на содержание и структуру юридической практики оказывает влияние появление новых юридических процедур. В частности, это порядок упрощенного производства в арбитражном процессе (гл. 29 АПК РФ); процедура ограничения распространения запрещенной информации в сети Интернет; процедура ограничения доступа к информации, содержащей призывы к массовым беспорядкам, осуществлению экстремистской деятельности, участию в массовых (публичных) мероприятиях, проводимых с нарушением установленного порядка; процедура ограничения доступа к информации, распространяемой с нарушением исключительных прав на фильмы, в том числе кинофильмы, телефильмы; процедура принятия предварительных обеспечительных мер защиты исключительных прав на фильмы, в том числе кинофильмы, телефильмы, в информационно-телекоммуникационных сетях, в том числе в сети Интернет.

Появившиеся новые юридические процедуры выражают внутреннюю форму юридической практики. Однако Интернет влияет и на внешнюю, документальную форму. Это выражается, например, в трансформации формы определений и решений арбитражных судов, содержащих QR-код и не требующих заверения подписью и печатью. Кроме того, процедуры ограничения распространения зап- рещенной информации включают в себя оперирование уведомлениями, часть из которых может существовать исключительно в электронной форме. Электронная форма распространяется и на дистанционную подачу документов в арбитражные суды.

Введение электронных форм судопроизводства способствует реализации процессуального приничипа гласности, а также общеправового принциипа законности. Кроме того, подобные процедуры существенно снижают нагрузку на судебную систему, оптимизируют ее работу, а также облегчают и ускоряют практическую деятельность юристов (например, использование электронного ресурса «Картотека арбитражных дел» - http:// kad.arbitr.ru/). На разрешение данных задач также направлено дистанционное оказание юридических услуг и дистанционное участие в судебном процессе (электронный ресурс «Мой арбитр» - my.arbitr.ru). Все вышеназванное обеспечивает доступ к правосудию физическим и юридическим лицам, а значит, приводит к увеличению объема и обогащению содержания юридической практики как накопленного социально-правового опыта.

\section{Влияние сети Интернет на правосознание}

Трансформация правосознания под влиянием сети Интернет в первую очередь связана с увеличением открытости правовой системы.

Рассматривая уровни правосознания, стоит отметить, что для теоретического правосознания Интернет создает новую предметную область изучения, объекты исследования, формирует новую картину правовой реальности, которая нуждается в научном осмыслении. Взаимопроникновение правового и интернет-пространства приводит к изменению не только их самих, но и представлений о них. Догматические положения о связи между формой и содержанием норм права, действием их в пространстве и по кругу лиц, роли государственного принуждения неизбежно корректируются с учетом новых реалий. Этим, к примеру, обусловлена популярность как в мировой, так и в российской юриспруденции доктрины мягкого права [3, с. 13-87; 4]. На са- 
мом деле идея о существовании, наряду с государственным принуждением, иных, несиловых средств правового воздействия не нова. Однако только сейчас доктрина оказалась готовой воспринять подобное несиловое действие права не как незначительное отклонение от нормы, побочное явление правовой реальности, а как полноценную и важную часть этой реальности. Причина этого, вероятно, в трансформации не только самого права, но и сознания ученых.

Что касается обыденного правосознания, то оно может трансформироваться как в сторону развития, так и в сторону деградации в зависимости от качества правовой информации, получаемой из сети Интернет. С одной стороны, восприятие права как чего-то более доступного и понятного, возможность самостоятельно найти подходящую норму, получить онлайн-консультацию, вступить во взаимодействие с государственными органами приводят к постепенному изменению отношения к праву. Последнее начинает восприниматься не столько (или не только) как инструмент государственного воздействия на общество, но и как средство, которое человек может использовать для защиты своих интересов и достижения своих целей. В совокупности с законодательными предписаниями Интернет обеспечивает открытость деятельности государственных органов, что, в свою очередь, ведет к подконтрольности государственного аппарата гражданскому обществу.

С другой стороны, Интернет может оказывать и негативное влияние на правосознание, выражающееся в его деформации. Так, анонимность в сети Интернет и массовый поток информации (в том числе нарушающей права иных субъектов) в свободном доступе влекут за собой развитие правового нигилизма.

При взаимодействии права и Интернета свое развитие получает и правовой фетииизм - стремление полностью регулировать Интернет государственно-правовыми методами. Восприятие этой идеи в обществе наглядно демонстрирует неоднородность общественного правосознания. Так, по данным социологов, массовое сознание достаточно лояльно относится к регулированию сети Интернет государственно-правовыми методами [10]. Более подробный анализ показывает принципиаль- ные расхождения по этому вопросу в сознании различных групп [8].

Таким образом, новая информация, проникающая в правовую систему, формирует идеи, влияющие на правосознание индивидов, групп, общества. Идейная и психологическая сферы правосознания в дальнейшем находят свое выражение как в правотворчестве, так и в правоприменении, функционирование которых обеспечивается развивающейся правовой инфраструктурой.

\section{Выводы}

Итак, сеть Интернет комплексным образом влияет на правовую систему, трансформируя ее структурные элементы. Стоит признать, что в основном данные изменения имеют позитивный характер, улучшая и развивая сложившиеся институты, а также создавая новые. С одной стороны, Интернет ставит перед правовой системой различные задачи, решение которых, выражая адаптивность, гибкость и динамизм, продвигает систему на новый уровень. С другой стороны, Интернет интегрирует в правовую систему, обладающую признаком открытости, новые возможности, механизмы, средства, отсутствовавшие ранее.

Заметим, что процесс взаимодействия сети Интернет и правовой системы начался сравнительно недавно, следовательно, обоюдная их трансформация еще далека от своего завершения и стабильного состояния.

\section{ПРИМЕЧАНИЕ}

\begin{abstract}
${ }^{1}$ Исследование выполнено при финансовой поддержке РФФИ и Администрации Волгоградской области в рамках научного проекта № 16-1334025 по «Технология электронного правительства в системе государственных и муниципальных услуг Волгоградской области: социально-правовое обеспечение эффективной реализации».
\end{abstract}

\section{СПИСОК ЛИТЕРАТУРЫ}

1. Давыдова, М. Л. Модернизация юридической техники российского права как ответ на вызовы наноиндустриализации / М. Л. Давыдова // Законы России: опыт, анализ, практика. -2011. -№ 9.-С. 66-72. 
2. Давыдова, М. Л. Проблемы и перспективы реализации проекта «Российская общественная инициатива» / М. Л. Давыдова // Вестник Волгоградского государственного университета. Серия 5, Юриспруденция. - 2015. - № 2 (27). - С. 58-67.

3. Демин, А. В. «Мягкое право» в эпоху перемен: опыт компаративного исследования / А. В. Демин. - М. : Проспект, 2016. - 240 с.

4. Захарова, М. В. «Твердая» почва для «мягкого» права / М. В. Захарова // Legal.Report. - Электрон. текстовые дан. - Режим доступа: https:// legal.report/author/tverdaya-pochva-dlya-myagkogoprava). - Загл. с экрана.

5. Карташов, В. Н. Теория правовой системы общества. В 2 т. Т. 1 / В. Н. Карташов. - Ярославль : ЯрГУ, 2005. - 547 с.

6. Макаров, В. О. Проблема юрисдикции правоотношений в сети Интернет / В. О. Макаров // Проблемы региона в исследованиях молодых ученых Волгоградской области : сб. науч. тр. / отв. ред. А. Р. Яковлев. - Волгоград : Изд-во ВолГУ, 2012.С. 302-305.

7. Модернизация технологий юридической деятельности в правовых системах современности: актуальные проблемы / ред. и предисл. М. А. Дамирли, М. Л. Давыдовой. - Волгоград : Изд-во ВолГУ, 2013. $-313 \mathrm{c}$.

8. Официальная позиция РАЭК // Российская ассоциация электронных коммуникаций. - Электрон. текстовые дан. - Режим доступа: http://raec.ru/times/ list/position/ (дата обращения: 28.08.2016). - Загл. с экрана.

9. Правовая система социализма: понятие, структура, социальные связи. В 2 кн. Кн. 1 / отв. ред. А. М. Васильев. - М. : Юридическая литература, 1986. $-386 \mathrm{c}$.

10. Россияне поддерживают цензуру в Интернете // Левада-центр. - Электрон. текстовые дан. Режим доступа: http://www.levada.ru/10-10-2012/ rossiyane-podderzhivayut-tsenzuru-v-internete (дата обращения: 28.08.2016). - Загл. с экрана.

11. Синюков, В. Н. Российская правовая система. Введение в общую теорию / В. Н. Синюков. 2-е изд., доп. - М. : Норма, 2014. - 679 с.

12. Федеральный закон «Об обеспечении доступа к информации о деятельности государственных органов и органов местного самоуправления» от 9 февр. 2009 г. № 8-Ф3 : (ред. от 09.03.2016) // Собрание законодательства РФ. - 2009. - 16 февр. № 7. - Ст. 776.

\section{REFERENCES}

1. Davydova M.L. Modernizatsiya yuridicheskoy tekhniki rossiyskogo prava kak otvet na vyzovy nanoindustrializatsii [Modernization of the Legal Technique of the Russian Law as a Response to the Challenges of Nanoindustrialization]. Zakony Rossii: opyt, analiz, praktika, 2011, no. 9, pp. 66-72.

2. Davydova M.L. Problemy i perspektivy realizatsii proekta "Rossiyskaya obshchestvennaya initsiativa" [Problems and Pprospects of Realization of the Project "The Russian Public Initiative"]. Vestnik Volgogradskogo gosudarstvennogo universiteta. Seriya 5, Yurisprudentsiya [Science Journal of Volgograd State University. Jurisprudence], 2015, no. 2 (27), pp. 58-67.

3. Demin A.V. "Myagkoe pravo" v epokhu peremen: opyt komparativnogo issledovaniya ["Soft Law" in an Era of Change: the Experience of Comparative Study]. Moscow, Prospekt Publ., 2016. 240 p.

4. Zakharova M.V. "Tverdaya" pochva dlya "myagkogo" prava ["Solid" Ground for a "Soft" Law]. Legal Report. Available at: https://legal.report/author/ tverdaya-pochva-dlya-myagkogo-prava. (accessed August 28, 2016).

5. Kartashov V.N. Teoriya pravovoy sistemy obshchestva. V 2 t. T. 1 [The Theory of Legal System of Society. In 2 vols. Vol. 1]. Yaroslavl, YarGU Publ., 2005. 547 p.

6. Makarov V.O. Problema yurisdiktsii pravootnosheniy v seti Internet [The Problem of Legal Jurisdiction in the Internet]. Yakovlev A.R., ed. Problemy regiona $v$ issledovaniyakh molodykh uchenykh Volgogradskoy oblasti: sbornik nauchnykh trudov [Problems of the Region in Young Scientists' Research of the Volgograd Region: Collection of Scientific Works]. Volgograd, Izd-vo VolGU, 2012, pp. 302-305.

7. Damirli M.A., Davydova M.L. Modernizatsiya tekhnologiy yuridicheskoy deyatelnosti v pravovykh sistemakh sovremennosti: aktualnye problemy [Modernization of Legal Activity's Technology in Modern Legal Systems: Current Problems]. Volgograd, Izd-vo VolGU, 2013.313 p.

8. Ofitsialnaya pozitsiya RAEK [The Official Position of RAEC]. Rossiyskaya assotsiatsiya elektronnykh kommunikatsiy [Russian Association of Electronic Communications]. Available at: http:// raec.ru/times/list/position/. (accessed August 28, 2016).

9. Vasilyev A.M., ed. Pravovaya sistema sotsializma: ponyatie, struktura, sotsialnye svyazi. $V 2$ kn. Kn. 1 [The Legal System of Socialism: the Concept, Structure, Social Networks. In 2 books. Book 1]. Moscow, 1986. 386 p.

10. Rossiyane podderzhivayut tsenzuru v Internete [Russians Support Censorship on the Internet]. Levada-tsentr [Levada Center]. Available at: http://www.levada.ru/10-10-2012/rossiyanepodderzhivayut-tsenzuru-v-internete. (accessed August 28, 2016). 
М.Л. Давыдова, В.О. Макаров. Трансформация правовой системы под влиянием сети Интернет

11. Sinyukov V.N. Rossiyskaya pravovaya sistema. Vvedenie vobshchuyu teoriyu [The Russian Legal System. Introduction to the General Theory]. Moscow, Norma Publ., 2014. 679 p.

12. Federalnyy zakon "Ob obespechenii dostupa $\mathrm{k}$ informatsii o deyatelnosti gosudarstvennykh organov i organov mestnogo samoupravleniya" ot 09.02.2009 № 8-FZ (red. ot 09.03.2016) [The Federal Law "On Providing Access to Information About the Activities of State Bodies" of February 9, 2009 no. 8FL (ed. of March 9, 2016)]. Sobranie zakonodatelstva $R F, 2009$, Feb. 16, no. 7, art. 776.

\section{Information About the Authors}

Marina L. Davydova, Doctor of Juridical Sciences, Professor, Head of Department of Constitutional and Municipal Law, Volgograd State University, Prosp. Universitetsky, 100, 400062 Volgograd, Russian Federation, davidovavlg@gmail.com,kmp@volsu.ru.

Vladislav O. Makarov, Lawyer of LEGION Bar Association of the Volgograd Region, 7 Gvardeyskoy Divizii St., 2, office 111, 400005 Volgograd, Russian Federation, makarov.legal@gmail.com.

\section{Информация об авторах}

Марина Леонидовна Давыдова, доктор юридических наук, профессор, заведующая кафедрой конституционного и муниципального права, Волгоградский государственный университет, просп. Университетский, 100, 400062 г. Волгоград, Российская Федерация, davidovavlg@gmail.com, kmp@volsu.ru.

Владислав Олегович Макаров, адвокат коллегии адвокатов Волгоградской области «ЛЕГИОН», ул. 7-й Гвардейской Дивизии, 2, оф. 111, 400005 г. Волгоград, Российская Федерация, makarov.legal@gmail.com. 